\title{
Preparation and characterization of a lithium ion conducting electrolyte based on poly(trimethylene carbonate)
}

\author{
Michael J. Smith ${ }^{\mathrm{a}}$, Maria Manuela Silva ${ }^{\mathrm{a}}$, Sandra Cerqueira ${ }^{\mathrm{a}}$ \\ James R. MacCallum ${ }^{\mathrm{b}}$ \\ a'Departamento de Química, Universidade do Minho, Largo do Paço, \\ 4700-320 Braga, Portugal \\ ${ }^{\mathrm{b}}$ School of Chemistry, University of St. Andrews, Fife, KY16 9ST, Scotland
}

\begin{abstract}
In this paper, the results of preliminary studies of two new solvent-free polymer electrolytes based on poly (trimethylenecarbonate), p TMC, with lithium trifluoromethanesulphonate, (triflate), and lithium perchlorate are described. Thin films of these electrolytes were obtained by evaporation of solvent from homogeneous mixtures of known masses of host polymer and salt. Electrolytes with compositions of $\mathrm{n}$ between 1.5 and 85, where $\mathrm{n}$ represents the molar ratio of $\left(\mathrm{O}=\mathrm{COCH}_{2} \mathrm{CH}_{2} \mathrm{CH}_{2} \mathrm{O}\right)$ units per lithium ion, have been prepared. These solvent-free electrolytes were characterized by measurements of total ionic conductivity, differential scanning calorimetry (DSC) and thermogravimetry (TGA) . As expected from previous studies with these salts in poly (ethylene oxide), PEO, the triflate-based system showed superior thermal stability but with a lower total ionic conductivity than that of the perchlorate-containing electrolyte. The highest conductivity approximately $3=10 \mathrm{Scm}^{-1}$ was found at $95^{\circ} \mathrm{C}$ with the electrolyte composition of (TMC) ${ }_{2} \mathrm{LiClO}_{4}$.
\end{abstract}

Keywords: lithium triflate, lithium perchlorate, solid polymer electrolytes, poly(trimethylene carbonate), thermal analysis, ionic conductivity.

\section{Conclusion}

A new host polymer matrix based on polycarbonate rather than polyether coordinating units, with lithium triflate and lithium perchlorate guest species, has been 
used to form solvent-free electrolytes. The highest ionic conductivity observed with the lithium perchlorate-based electrolyte at a salt-rich composition, is slightly lower than that observed in several solvent-free systems based on PEO.

The results of thermal analysis have confirmed that polymer electrolytes based on this host matrix are completely amorphous. Within the range of temperatures studied (-40 to $350^{\circ} \mathrm{C}$ ), the only thermal events observed correspond to glass transition and thermal degradation of the polymer electrolyte. All electrolyte samples showed an adequate window of thermal stability for practical devices; however, in view of the exothermic degradative reaction of the perchlorate anion, it is unlikely that electrolytes based on this guest species will be of commercial interest.

While the total ionic conductivity and mechanical properties of this new solid polymer electrolyte are encouraging, there are several other parameters which must be considered before the host polymer is accepted as of potential interest in practical devices. Clearly, other aspects of electrolyte performance that are of practical importance are the lithium ion transference number, the electrochemical stability and compatability with electrode materials. The study of these properties, together with the behaviour of electrolytes based on more viable guest salt species and the influence of various conductivity-enhancing additives, is currently underway.

\section{References}

1. J.R. MacCallum, C.A. Vincent Eds., Polymer Electrolyte Reviews, vol. 1, Elsevier, London, 1987.

2. J.R. MacCallum, C.A. Vincent Eds., Polymer Electrolyte Reviews, vol. 2, Elsevier, London, 1989.

3. F.M. Gray, Solid Polymer Electrolytes: Fundamentals and Technological Applications, VCH, New York, 1991.

4. B. Scrosati Ed., Applications of Electroactive Polymers, Chapman \& Hall, London, 1993.

5. R.G. Linford Ed., Electrochemical Science and Technology of Polymers, vol. 1, Elsevier, London, 1987. 
6. R.G. Linford Ed., Electrochemical Science and Technology of Polymers, vol. 2, Elsevier, London, 1991.

7. F.M. Gray, Polymer Electrolytes, RSC Materials Monographs, Royal Society of Chemistry, London, 1997.

8. D.E. Fenton, J.M. Parker, P.V. Wright, Polymer 14 (1973) 589.

9. P.V. Wright, Br. Polym. J. 7 (975) 319.

10. M.B. Armand, J.M. Chabagno, M.J. Duclot, 2nd International Conference on Solid Electrolytes, St. Andrews, Paper 6, (1978) 5.

11. T. Yamamoto, M. Inami, T. Kanbara, Chem. Mater. 6 (1994) 44. 